\title{
História da Educação Matemática e a formação de professores primários: ensino de medidas ${ }^{1}$
}

\author{
History of Mathematical Education and elementary \\ teacher training: measurement teaching
}
Historia de la Educación Matemática y la formación de profesores primarios: enseñanza de medidas

MARIA CÉlIA LEME DA SILVA ${ }^{2}$

\section{Resumo}

O estudo busca responder às questões: De que maneira o conhecimento da história da educação matemática pode contribuir para as reflexões e desafios postos nos documentos atuais? Para tanto, analisa-se como a medida de superfícies em dois momentos históricos: final do século XIX, período caracterizado pela pedagogia moderna e início do século XXI no âmbito do Plano Nacional de Alfabetização. As fontes examinadas são: Caderno do PNAIC (2014), Parecer de Rui Barbosa (1883) e a Proposta de Gabriel Prestes (1895, 1896). Propõese pensar e conhecer os saberes matemáticos elementares do passado em seu contexto histórico, perceber que a institucionalização da expertise participa poderosamente da produção de novos saberes no campo pedagógico, porém seu processo de legitimação, de reconhecimento por seus pares é longo, complexo e conflituoso.

Palavras-chave: PNAIC, Rui Barbosa, Gabriel Prestes. Expertise.

\footnotetext{
${ }^{1}$ Versão revisada e ampliada do texto apresentado no GT19 - Educação Matemática durante a $38^{\mathrm{a}}$ Reunião Nacional da ANPEd. Pesquisa desenvolvida com apoio financeiro da FAPESP.

${ }^{2}$ Doutorado em Educação (Currículo) pela Pontifícia Universidade Católica de São Paulo, com estágio de pós-doutorado concluídos na Universidade Nova de Lisboa (Portugal) e na Université Paris-Sud 11 (França). Professora Adjunta na Universidade Federal de São Paulo (Diadema). E-mail: mcelialeme@gmail.com
} 


\begin{abstract}
The study seeks to answer the questions: How can the knowledge of the history of mathematics education contribute to the reflections and challenges posed in the current documents? To this end, it is analyzed as the measurement of surfaces in two historical moments: the end of the nineteenth century, a period characterized by modern pedagogy and the beginning of the 21st century within the scope of the National Literacy Plan. The sources examined are: Notebook of the PNAIC (2014), Opinion of Rui Barbosa (1883) and the Proposal of Gabriel Prestes (1895, 1896). It is proposed to think and know the elementary mathematical knowledge of the past in its historical context, to realize that the institutionalization of expertise participates powerfully in the production of new knowledge in the pedagogical field, but its process of legitimation, recognition by its couple is long, complex and conflicting.
\end{abstract}

Keywords: PNAIC, Rui Barbosa, Gabriel Prestes. Expertise.

\title{
Resumen
}

El estudio busca responder a las preguntas: ¿De qué manera el conocimiento de la historia de la educación matemática puede contribuir a las reflexiones y desafios planteados en los documentos actuales? Para ello, se analiza como la medida de superficies en dos momentos históricos: final del siglo XIX, período caracterizado por la pedagogía moderna e inicio del siglo XXI en el marco del Plan Nacional de Alfabetización. Las fuentes examinadas son: Cuaderno del PNAIC (2014), Dictamen de Rui Barbosa (1883) y la Propuesta de Gabriel Prestes (1895, 1896). Se propone pensar y conocer los saberes matemáticos elementales del pasado en su contexto histórico, percibir que la institucionalización de la expertise participa poderosamente de la producción de nuevos saberes en el campo pedagógico, pero su proceso de legitimación, de reconocimiento por sus pares es largo, complejo y complejo, conflicto.

Palabras clave: PNAIC, Rui Barbosa, Gabriel Prestes. Expertise. 
No texto "A produção internacional em história da educação matemática" o pesquisador Gert Schubring (2012) assinala como referência para a constituição da área, o estabelecimento do Topic Study Group: The History of Teaching and Learning Mathematics, no âmbito do $\operatorname{ICME}^{3}$ 10, no ano 2004, em Copenhaguen. No Brasil, tais estudos e investigações vêm ganhando reconhecimento enquanto campo específico de produção científica ${ }^{4}$, com estudos que revelam a produção de histórias sobre como se deu o ensino de matemática, em diferentes níveis de ensino e nos diversos momentos históricos.

Entretanto, o diálogo da produção de história da educação matemática com a formação de professores é ainda inicial, uma discussão de como os resultados de pesquisa podem e devem ser inseridos na formação de professores que ensinam matemática foi objeto de debate no III ENAPHEM ${ }^{5}$ e resultou em dois artigos com posicionamentos diversos, a criação de uma disciplina a ser inserida em cursos de graduação e pós-graduação (Oliveira, 2017) e outro, que defende a possibilidade de outras formas de ação, diferentemente de uma disciplina específica (Garnica, 2017).

Sem tomar posicionamento sobre o lugar da história da educação matemática, o presente estudo tem por objetivo apresentar como saberes escolares discutidos na atualidade foram abordados em tempos passados e a partir de então, problematizar a questão: de que maneira o conhecimento da história de um saber pode contribuir na formação de professores primários hoje?

O saber em questão é a medida de área de paralelogramos, tomado como um exemplo para a reflexão sobre problemáticas e abordagens atuais e do passado. Inicia-se com uma análise sobre o Caderno Grandezas e Medidas publicado no âmbito do PNAIC - Plano Nacional de Alfabetização na Idade Certa em 2014 e toma-se como fonte histórica o cenário do final do século XIX em São Paulo, analisando três documentos: o parecer de Rui Barbosa, publicado em 1883, um manual destinado aos professores primários intitulado Noções Intuitivas de Geometria Elementar de Gabriel Prestes, de 1895, assim como artigo publicado pelo mesmo autor na Revista A Eschola Publica de 1896.

$\mathrm{O}$ estudo busca responder às questões: Como a medida de superfícies foi abordada no final do século XIX, período caracterizado pela pedagogia moderna? De que maneira o conhecimento da história da educação matemática pode contribuir para as reflexões e desafios postos nos documentos atuais?

\section{PNAIC - Plano Nacional de Alfabetização na Idade Certa}

O Caderno de número 06, Grandezas e Medidas, publicado pelo Ministério da Educação tem como objetivo discutir e disponibilizar aos professores primários possibilidades de trabalhar o eixo Grandezas e Medidas, considerando os seus diferentes contextos. O Caderno oferece inúmeros relatos de experiências realizadas por professores, sugestões de

\footnotetext{
${ }^{3}$ International Congress on Mathematical Education.

${ }^{4}$ Citam-se os eventos já realizados sobre a temática: I CIHEM - Congresso Iberoamericano de História da Educação Matemática (Covilhã, Portugal, 2011), II CIHEM (Cancún, México, 2013) e III CIHEM (Belém, Brasil, 2015) e I ENAPHEM - Encontro Nacional de Pesquisas em História da Educação Matemática (Vitória da Conquista, BA, 2012), II ENAPHEM (Bauru, SP, 2014) e III ENAPHEM (São Mateus, ES, 2016).

${ }^{5}$ Encontro Nacional de Pesquisa em História da Educação Matemática, realizado em 2016.
} 
atividades, leituras, discussões que podem contribuir e favorecer o ensino das grandezas e medidas, de modo geral, envolvendo diversos tipos de grandezas, tais como: comprimento, massa, capacidade, temperatura e tempo. Uma das primeiras considerações apontadas pelos autores $^{6}$ é a importância da atuação participativa das crianças em atividades de medida:

a necessidade absoluta de trabalhos nos quais as crianças se ponham mobilizadas em práticas efetivas de medições. Pouco adianta o professor construir materiais para as crianças apenas olharem, e pouco adianta o professor "falar sobre" o conteúdo que as crianças devem aprender sem que elas façam medições e adquiram o hábito de conversar entre elas sobre os resultados obtidos. (BRASIL, 2014, p. 11, grifo nosso).

As sequências didáticas a serem trabalhadas com os alunos, além de incentivar a prática efetiva de medidas, ressalta a relevância da testagem de diferentes unidades de medidas para a mesma grandeza, além da medição com padrões não convencionais, como palmos, pés, cuias, de modo a perceber a necessidade de "unidades de medida", assim como de seu fracionamento.

Em relação à Educação Fundamental, o documento salienta que o ensino e aprendizagem das medidas "tem sido uma das mais frustrantes experiências para alunos e professores" (BRASIL, 2014, p.13), apontando dificuldades em converter uma unidade em outra e no uso de fórmulas. Destaca-se ainda que o objetivo do ciclo de alfabetização (três primeiros anos do Ensino Fundamental) é privilegiar a construção da noção de grandeza e de medida, adotando uma abordagem adequada do ponto de vista conceitual e didático neste ciclo de modo a minimizar obstáculos nos ciclos posteriores. O Caderno apresenta muitas sugestões de atividades para serem trabalhadas em sala de aula, sem, contudo, organizar temas e conteúdos em uma ordem fixa, entretanto, ressalta que "os Direitos de Aprendizagem das crianças de 6 a 8 anos prevêem que elas sejam capazes de experimentar situações cotidianas ou lúdicas, envolvendo diversos tipos de grandezas" (BRASIL, 2014, p. 5).

Como exemplo de problema no ensino de medidas, decorrentes da falta de um trabalho sistemático, o Caderno relata depoimento de uma professora de Curitiba, ocorrido na oitava série, ao solicitar, aos alunos, uma planta de casa cuja área fosse de $200 \mathrm{~m}^{2}$ :

O conceito de área é trabalhado, regularmente, desde muito cedo, mas infelizmente sem qualquer apelo prático: aprende-se que a área do quadrado é lado ao quadrado, e que a área de um retângulo é um lado vezes o outro. $\mathrm{O}$ resultado dessa "falta de experiência" foi que todos os alunos da turma fizeram plantas de casas com 4 ou 5 peças, não tinham a mínima noção de que uma casa com $200 \mathrm{~m}^{2}$ seria uma "mansão" para o tamanho dos cômodos aos quais estavam acostumados, podendo resultar numa casa com 10 cômodos ou mais. (BRASIL, 2014, p. 32, grifo nosso).

\footnotetext{
${ }^{6}$ Carlos Roberto Vianna, Danilo Pereira Munhoz, Eliane Costa Santos, Emerson Rolkouski, Keli Mota Bezerra, Júlio César do Valle, Mabi Katien Batista de Paula, Mara Sueli Simão Moraes, Maria do Carmo Santos Domite, Régis Luíz Lima de Souza, Rodrigo Abreu, Valdirene Rosa de Souza, Vanisio Luiz Silva.
} 
De modo geral, pode-se dizer que a ênfase da proposta veiculada no Caderno está no caráter prático do ensino, na importância da participação do aluno no processo de ensino, de modo que ele possa efetuar de maneira prática medidas diferenciadas, comparar. Para além da prática associada à atividade física de executar medidas, há também a necessidade de relacionar, associar e discutir o ensino de medidas com as situações da prática cotidiana, do preparar e capacitar os alunos para atividades da vida prática, como o exemplo relatado pela professora.

Uma pergunta que se coloca frente a tal questão é como o caráter prático foi abordado em tempos passados, em relação ao ensino de grandezas e medidas? Particularmente, toma-se, como exemplo, o caso da grandeza superfície e o período do final do século XIX para a discussão. A escolha do período deve-se por ser um momento importante na organização do sistema educacional brasileiro, a reunião de escolas isoladas num novo modelo de escola primária denominada de "grupo escolar", em 1893. O período ainda inaugura a chegada dos princípios da pedagogia moderna aos programas de ensino. De acordo com Carvalho (2000), a pedagogia moderna caracteriza-se pela arte de ensinar, organiza-se sob o primado da visibilidade, tendo a lógica do ensino centrada no exercício escolar, as revistas pedagógicas estruturam-se como caixas de utensílios para uso dos professores, com seções de prática compostas por roteiros ou modelos de lições aos professores.

\section{Parecer de Rui Barbosa}

A Reforma do Ensino Primário e Secundário da Corte, de 19 de abril de 1879 assinada pelo ministro Leôncio de Carvalho motivou inúmeros debates ao ser apreciado pelo Legislativo, resultando na elaboração de um parecer para subsidiar a discussão. Rui Barbosa ${ }^{7}$ foi designado como relator dos pareceres ${ }^{8}$ apresentados ao parlamento brasileiro, no ano de 1882. O documento, que ficou conhecido como parecer de Rui Barbosa é considerado emblemático no processo de reforma do ensino primário e serve de referência para os republicanos nos debates e proposições sobre a educação popular no final do Império (SOUZA, 2009).

Ao discutir a matemática elementar a ser ensinada no curso primário, Rui Barbosa propõe afastar-se do caráter abstrato, em substituição ao sentimento, intuição da proporcionalidade, contribuindo também para o ensino elementar da geometria. Sugere para a entrada na escola, o curso concreto, intuitivo, começando por discernir as formas geométricas

\footnotetext{
${ }^{7}$ Rui Barbosa (1849-1923) foi advogado, homem de estado, orador, jornalista, homem de letras. Os escritos de Rui Barbosa sobre educação compreendem um período limitado de sua trajetória política como reformador social e entre elas, destacam-se o parecer sobre a reforma do ensino primário escrito em 1882, publicado em 1883 e a tradução do livro de orientações didáticas de N.A. Calkins - Primeiras Lições de Coisas, traduzido em 1881 e publicado em 1886. (BASTOS, 2000, p. 84).

${ }^{8}$ Rui Barbosa apresentou ao parlamento brasileiro dois pareceres em 1882: um sobre a reforma do ensino primário e outro sobre o ensino secundário e superior. O parecer sobre o ensino primário data de 12 de setembro de 1882, mas a publicação do volumoso incluindo os anexos foi concluída em 1883, data efetiva de aparecimento desse documento. (SOUZA, 2009, p. 75).
} 
mais elementares, o sistema froebeliano ${ }^{9}$ que adestra os meninos na reprodução de formas geométricas em papelão, terra plástica etc., de modo a discernir as combinações geométricas das linhas, superfícies e sólidos, para que no segundo grau seja introduzida a taquimetria:

Inteiramente ignorada até hoje entre nós na prática do ensino, a taquimetria encerra em si o único sistema capaz de tornar a ciência geométrica um elemento universal de educação popular. A taquimetria é a concretização da geometria, é o ensino da geometria às inteligências mais rudimentares: é a lição de coisas aplicada à medida das extensões e volume. (BARBOSA, TOMO II, 1883, p. 290, grifos do autor).

Rui Barbosa cita Eduardo Lagout, engenheiro de pontes e calçadas francês, como criador do método taquimétrico, com longa experiência e alto merecimento e adaptabilidade específica ao ensino elementar, ressalta que na França a taquimetria ocupa fortemente a atenção da instrução pública, e finalmente conclui que "o método taquimétrico é, portanto, a mais rigorosa, a mais chã a mais praticável adaptação das leis da pedagogia intuitiva ao ensino popular da geometria, à instrução geométrica das crianças" (BARBOSA, TOMO II, 1883, p. 291).

Nota-se, na proposta, o destaque dado ao caráter prático advindo das medidas associadas as extensões e volumes, como um direcionador do ensino de geometria para o curso primário. É preciso ainda considerar que a taquimetria, segundo Barbosa, insere-se no estudo da geometria ${ }^{10}$, de forma integrada.

\section{Manual de Gabriel Prestes}

Como já dito o parecer de Rui Barbosa é considerado referência nas reformas educacionais paulistas após a Proclamação da República, em 1889. De acordo com Monarcha (1999), o novo edifício construído para a Escola Normal de São Paulo representa a instalação e expansão da cultura escolar urbana paulista da virada do século:

O deputado-normalista Gabriel Prestes, eleito pelo Partido Republicano Paulista, renuncia ao seu mandato parlamentar para assumir, em outubro de 1893, o cargo de diretor da Escola Normal. A gestão administração de Gabriel Prestes (1893-1898) - representa o "período áureo da instrução pública paulista". Formado pela Escola Normal, "positivamente educado" Prestes coloca termo às flutuações do instituto", exercendo quase plena ditadura espiritual" sobre a Escola Normal (MONARCHA, 1999, p. 201).

\footnotetext{
${ }^{9}$ Friedrich Froebel (1782-1852). No Brasil, na segunda metade do século XIX, principalmente a partir da década de 1870, as ideias de Froebel começaram a ser divulgadas. Bastos destaca a importância de conhecer e refletir sobre as bases filosófico-pedagógicas que orientaram a ideia dos jardins de infância e da pedagogia do brinquedo. Para Popkewitz, a pedagogia de Froebel, influenciada por Pestalozzi e Rousseau, defendia a ideia de que as crianças são naturalmente inocentes e boas e que os métodos de educação deveriam protege-las dos perigos de um mundo corrupto (BASTOS, 2001, p. 7).

${ }^{10}$ Vale considerar que no PNAIC (2014), a Geometria é tradada no Caderno 5 e Grandezas e Medidas, no Caderno 6, separadamente.
} 
Assim sendo, a Escola Normal da Praça transforma-se em símbolo da República e da superioridade do estado de São Paulo. Ao ocupar a direção da Escola, Gabriel Prestes exerce papel de poder e de liderança. Segundo Hofstetter et al (2017), a entrada em cena do Estado encarregado da instrução pública configura a institucionalização da expertise, entendida como:

A expertise é, portanto, realizada por pessoas do meio escolar, isto é, pela profissão docente. [...] o trabalho de expertise se aperfeiçoa e desenvolve fortemente os saberes que lhe dizem respeito; procedimentos, análises, testes tornam-se um produto coletivo. [...]. Esta expertise é solicitada pelas autoridades do ensino tendo em vista a necessidade de tomar uma decisão. A solicitação de expertise, veremos, participa poderosamente da produção de novos saberes no campo pedagógico (HOFSTETTER ET AL, 2017, p. 67-68, p. 80).

Assim, é neste contexto que se examina a produção de Gabriel Prestes, como um possível expert da educação, responsável pela implementação das novas propostas pedagógicas que circulam no Brasil do final do século XIX e que toma a Escola Normal como um modelo de formação de professores:

A organização de uma Escola Normal é, por sua natureza, extremamente complexa. A formação de professores baseia-se num curso teórico, que tem forçosamente de acompanhar, nos seus elementos, a evolução da ciência contemporânea, e num tirocínio prático, que, para ser completo, pressupõe a existência de instituições de ensino primário e integral nos seus dois elementos constitutivos: educação e ensino (PRESTES, 1896, p.3-4 apud MONARCHA, 1999, p. 206).

Gabriel Prestes publica o Manual Noções Intuitivas de Geometria Elementar ${ }^{11}$, em 1895, destinado a servir de guia aos professores primários que queiram buscar alguma indicação prática. No prefácio do próprio autor, fica claro o seu contato com obras estrangeiras, Prestes inicia com citação do livro de Clairaut, comenta sobre os estudos de Eduardo Lagout e do matemático Dalsème, como criadores do sistema taquimétrico, no entanto, ao tomar contato com o livro Premiers Éléments de Géometrie Expérimentale de Paul Bert, abandona as ideias anteriores por considerar este um livro que se destina à leitura das crianças. Tudo indica que o manual de Prestes para o ensino de uma geometria intuitiva trata-se de uma adaptação e apropriação da obra de Paul Bert, de modo a atingir o seu propósito:

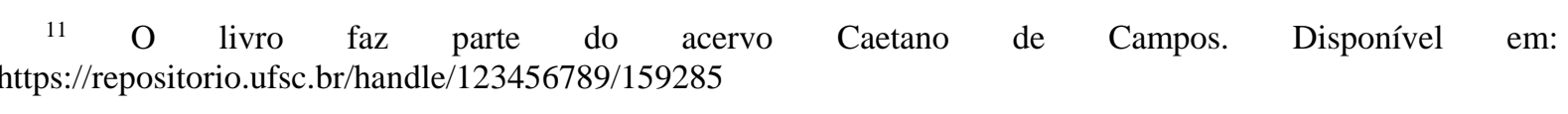


procurei fazer a aplicação prática dos preceitos estabelecidos, figurando-me, as mais das vezes, na posição do professor que tem deante de si uma classe de alumnos cuja attenção é preciso captivar, interessando-os pelo objeto das lições e cuja actividade intellectual é mister encaminhar logica e naturalmente, sem constrangel-a, mas tambem sem abandonal-a a si mesma. (PRESTES, 1895, p. 12).

O manual é publicado em São Paulo, pelo editor Horácio Belfort Sabino, destinado para o segundo ano das escolas preliminares. Contém 95 páginas, distribuídas em tópicos: Prefácio, Ordem a seguir na Geometria, Da linha reta, das curvas e ângulos, Da formação das linhas. Superfícies, Modo de fazer as recapitulações, Medida direta das superfícies, Superfícies curvas, Recapitulação abstrata, Diversos sólidos, Medida directa dos volumes e Conclusão.

Pode-se ler a postura de Prestes no que diz respeito à Geometria, desde o prefácio de seu manual, em que tece críticas ao ensino da Geometria que parte de definições, princípios fundamentais e postulados, por não serem compreensivos às crianças, sem, contudo, deixar de valorizar a importância de seu caráter abstrato:

Mas a Geometria, pela natureza deductiva do seu methodo, só pode ser iniciada com proveito quando o espírito chegar ao grau de desenvolvimento preciso, quando a intelligencia adquirir a faculdade de abstracção necessaria para só considerar as propriedades geometricas e deduzir dellas todas as consequencias que, sem aplicação pratica immediata, servem comtudo para formar um systema de verdades, homogeneo e logicamente perfeito, indispensavel como disciplina mental e importantissimo pelas suas applicações posteriores. Como pois, conciliar as exigencias deste ensino abstracto com a possibilidade de inicial-o desde logo nas escolas? (PRESTES, 1895, p. 8).

Gabriel Prestes responde à questão da citação acima no seu primeiro tópico - Ordem a seguir na Geometria - em que ele propõe uma nova ordem ao ensino da geometria. É preciso ressaltar que o manual é elaborado para alunos do segundo ano da escola primária e no prefácio, o autor sugere que o primeiro ano seja "consagrado ao desenvolvimento da percepção pelo ensino intuitivo das fórmas geometricas, systema de Calkins ${ }^{12}$ ou de Prang (PRESTES, 1895, p. 12-13).

Segundo Prestes, os alunos são capazes de reconhecer as diversas espécies de grandezas cuja medida constitui o objeto da Geometria, eles não apresentam dificuldade em distinguir uma linha, uma folha de papel e um copo. E a Geometria, tem por fim medir tais grandezas: linhas, superfícies e volumes. A partir da explicação de que qualquer que seja a forma de um corpo, sempre existe um número de linhas, cuja extensão é suficiente para definir a grandeza da sua superfície ou do seu volume, ele esclarece sua proposta:

${ }^{12}$ Um estudo mais aprofundado sobre o manual de Calkins pode ser lido em FRIZZARINI, LEME DA SILVA (2016). 
Assim, o objecto geral da Geometria, relativamente ás superfícies e aos volumes, é propriamente reduzir todas as comparações de superfícies e volumes a comparação de linhas"13 (PRESTES, 1895, p. 17).

Fica, portanto, assentado como ponto de partida que as três grandezas que vamos estudar são assimilaveis e que a simples dimensão linear serve para caracterizal-a (Ibid, p. 18).

Em síntese o que está em questão é a inserção do estudo das grandezas e as respectivas medidas como elementar para o ensino de Geometria. Trata-se de atribuir para tais saberes grandezas e medidas - o lugar de início do ensino, de base para os estudos futuros e neste sentido, compreende-se o destaque no primeiro tópico para a "Ordem a seguir na Geometria". Sua proposta sustenta-se por uma nova marcha no ensino.

Definida a ordem, outra questão se coloca, como o professor deve apresentar ao aluno as noções de linha, superfície e volume? Para Prestes, a maneira como tais noções são apresentadas não pode ser realizada teoricamente e sim intuitivamente, partindo do concreto, como processo educativo. E novamente, ele reitera a crítica em relação a ordem estabelecida nos compêndios de Geometria: estudo das linhas com todas as propriedades, em seguida o estudo das superfícies e por último, inicia-se o estudo do volume. Em confronto ao tido como marcha normal, Prestes justifica, uma vez mais, a proposta de mudança:

Neste primeiro ensino, porem, como já disse, ha vantagem no confronto das tres grandezas que se trata de estudar. Alem disso o conhecido para a criança não coincide exactamente com o mais simples, porque o espirito infantil impressionado pelos objectos que o rodeiam adquiriu conjuntamente noções relativas ás linhas, ás superfícies e aos volumes. (PRESTES, 1895, p. 20).

A ordem estabelecida e consequentemente a escolha dos elementares, dos saberes que constituem o início do ensino, pauta-se na concepção de educação. $O$ pesquisador Alain Trouvé (2008) analisa a noção de saber elementar a partir de duas abordagens filosóficas: racionalista e empirista. Segundo o autor, a pedagogia racionalista adota como centro as concepções de valores e ideias da razão e do saber, enquanto a pedagogia empirista privilegia a experiência e o sujeito. $\mathrm{O}$ autor também ressalta que a primeira abordagem, a racionalista, considera que o simples reside na abstração, enquanto que a segunda, a empirista, estima o simples na concretude.

Para pedagogia racionalista, o elementar e a ordem a ser seguida são determinados pela ciência de referência, no caso em questão, a lógica dedutiva da Geometria. Já a pedagogia empirista, o elementar e a marcha do ensino é fundamentada no indivíduo que aprende e na maneira como se dá a aprendizagem. A posição de Gabriel Prestes, ao propor o estudo conjunto de linhas, superfícies e volumes, leva em conta o espírito infantil e assim

\footnotetext{
${ }^{13}$ Prestes insere nesta citação uma nota de rodapé - Philosophie Positive, vol. I, pag. 263.
} 
parece ser clara a sua filiação pela pedagogia empirista. Para estruturar sua proposta, mesmo que o livro seja somente para o segundo ano, Prestes propõe uma nova abordagem para o ensino das medidas, distribuídas em:

Quadro 1 - proposta de distribuição para o ensino de Geometria de Prestes

\begin{tabular}{|c|l|}
\hline $2^{\circ}$ ano & $\begin{array}{l}\text { Ideia geral das três grandezas - linhas, superfícies e volumes; medidas diretas } \\
\text { feito por processos espontâneos. }\end{array}$ \\
\hline $3^{\circ}$ ano & $\begin{array}{l}\text { Medida indireta das linhas, estudando por meio de aplicações as suas } \\
\text { propriedades principais, medida indireta das superfícies e dos volumes } \\
\text { deduzidos a partir dos processos espontâneos. }\end{array}$ \\
\hline $4^{\mathrm{o}}$ ano & $\begin{array}{l}\text { Medida indireta da circunferência, da área do círculo, do volume dos corpos } \\
\text { terminados por superfícies curvas. }\end{array}$ \\
\hline
\end{tabular}

Fonte: Construído pelo autor a partir do prefácio do manual de Gabriel Prestes (1895)

A distribuição da Geometria a ensinar ${ }^{14}$ de Gabriel Prestes para o curso primário não corresponde ao programa de ensino, publicado em 1894, um ano antes da publicação de seu livro. O programa de $1894^{15}$, conforme o quadro 2 abaixo, apresenta exatamente a distribuição que Prestes comenta e tece críticas, presente nos compêndios de Geometria, em que se inicia com as linhas nos dois primeiros anos, a superfície é introduzida somente no $3^{\circ}$ ano e o volume é apresentado no $4^{\circ}$ e último ano do curso preliminar.

Quadro 2 - distribuição das medidas no programa de 1894 para as escolas preliminares.

\begin{tabular}{|c|c|}
\hline $1^{\circ}$ ano & Systema metrico - Mostrar o metro e exercícios práticos, medindo fitas e chitas. \\
\hline $2^{\circ}$ ano & Systema metrico - Metros : multiplos e sub-multiplos. \\
\hline $3^{\circ}$ ano & $\begin{array}{l}\text { Ponto, extensão sem dimensão. Linha, uma dimensão. Comprimento. Superficie - } \\
\text { duas dimensões. Solido - tres dimensões. } \\
\text { Medida da superfície do quadrado. Rectangulo: idem }\end{array}$ \\
\hline $4^{\circ}$ ano & $\begin{array}{l}\text { Superfície do triângulo. Applicação pratica em superfícies polygonaes. Medida da } \\
\text { superfície dos polygonos. Medida do perímetro dos polygonos regulares. } \\
\text { Calculo da circumferencia e da superfície do circulo. Volume do cubo. Volume do } \\
\text { prisma recto. Prisma oblíquo: seu volume.șẹp:Pyramide: seu volume. Cylindro: seu } \\
\text { volume. Esphera: seu volume. }\end{array}$ \\
\hline
\end{tabular}

Fonte: Construído pelo autor a partir do programa de ensino do Estado de São Paulo de 1894.

\footnotetext{
${ }^{14}$ Geometria a ensinar é empregado em acordo com Hofstetter e Schneuwly (2009), ou seja, como os saberes que são objeto do trabalho docente.

${ }^{15}$ Decreto 248 de 26 de julho de 1894 - Approva o regimento interno das escolas públicas. Assinada por Bernardino de Campos, presidente do Estado de São Paulo.
} 
Pode-se dizer que a proposta de geometria intuitiva de Prestes exibe uma marcha de ensino diferenciada, ao trazer as grandezas e medidas como elementos de base para o ensino da Geometria. Trata-se de uma nova organização da geometria a ensinar na escola primária brasileira, sustentada pela importância do conhecido para a criança, do espirito infantil impressionado pelos objetos que o rodeiam, de modo a "substituir" o mais simples do ponto de vista racional.

E como Gabriel Prestes apresenta em seu livro o desenvolvimento do estudo das linhas, superfícies e volumes em conjunto destinado ao $2^{\circ}$ ano do curso primário? Como o próprio autor ressalta, é preciso apresentar e desenvolver tais noções intuitivamente. Ressalta-se que na proposta de Prestes o segundo ano deve trabalhar com medidas diretas feitas por processos espontâneos. Como já dito, tomar-se-á, como exemplo, a proposta para a medida de superfícies.

A partir de uma régua e de uma prancheta, o autor explica o que vem a ser a superfície plana, sempre oferecendo outros exemplos da realidade do aluno, como as paredes, mesas, em se pode aplicar a régua em qualquer direção, para então conceituar "Só então explico o que é superfície plana, dizendo que a parte da plancheta, da parede, das mesas em que a régua fica bem assentada chama-se superfície plana." (PRESTES, 1895, p. 40). Indica os termos equivalentes, como plano, chato, liso e sugere que as crianças criem frases com essas palavras.

A noção de medida direta de superfície inicia-se pela construção, a partir de uma folha de papel, de um quadrado de uma polegada de lado, explicando que o quadrado por medir uma polegada de comprimento e largura, representa uma polegada quadrada. Prestes sugere que o professor corte vários quadrados iguais para então realizar a medida de uma pedra, de modo a ir cobrindo a superfície com os quadrados de papel. O diálogo proposto por Prestes durante a atividade:

- Quantas polegadas quadradas cabem na pedra? Qual é então a medida da superfície da pedra?

- Tem 42

- Muito bem, mas não ficou um pedaço da pedra sem medir? Pode-se medir esse pedaço que falta com a polegada? Por que não o podemos medir?

- Porque a polegada é maior

- Então o que é preciso para medir?

- Muito bem ..., para medir o que falta é preciso um outro quadrado de papel menor que a polegada quadrada (PRESTES, 1895, p. 60-61)

Prestes insiste para que o professor obtenha situações em que a medida empregada não seja suficiente, de modo a explorar a necessidade de outras unidades. Nas conclusões do manual, Prestes evidencia que sua proposta não teve o propósito de criar um molde inflexível, do qual o professor não possa se afastar. Ao contrário, sua intenção foi de "indicar os pontos que, perante a lógica, parecem essenciais, e que ao professor, servirão de advertencia para methodizar o seu ensino" (1895, p. 94). 


\section{Artigo de Gabriel Prestes}

Um ano após a publicação do livro de Gabriel Prestes, o mesmo autor publica artigo na Revista A Eschola Publica, intitulado Noções Intuitivas de Geometria elementar para o terceiro ano do ensino preliminar - Mediada Indirecta das superfícies, dando continuidade a proposta desenvolvida em seu livro. $\mathrm{O}$ artigo inicia com a recapitulação do estudo proposto para o segundo ano do curso primário - medida direta das superfícies, que consiste em cobrir uma superfície com uma unidade de referência.

Os exemplos sugeridos no artigo para a recapitulação propõem a medida da área de um quadrado e de um retângulo. Nas duas situações, discute-se uma outra maneira de encontrar a medida da superfície sem contar a quantidade de quadradinhos usados para cobrir a superfície toda, de modo a levar os alunos a perceberem que a medida da superfície de um quadrado é obtida pela multiplicação da medida da base pela altura. Assim como no livro, discute-se a situação de medidas não inteiras.

Feita a retomada, Prestes apresenta o paralelogramo, explorando suas propriedades, semelhanças e diferenças em relação ao quadrado e retângulo, já estudados no segundo ano. A seguir, para demonstrar a equivalência da área do paralelogramo e do retângulo de mesma base e altura, Prestes propõe "o processo da justaposição, o mais natural e o único verdadeiramente intuitivo" (PRESTES, 1896, p. 381), que corresponde a justaposição de dois triângulos retângulos iguais, em diferentes posições, de modo que o aluno perceba a equivalência entre as superfícies do retângulo e do paralelogramo, conforme extrato do artigo:

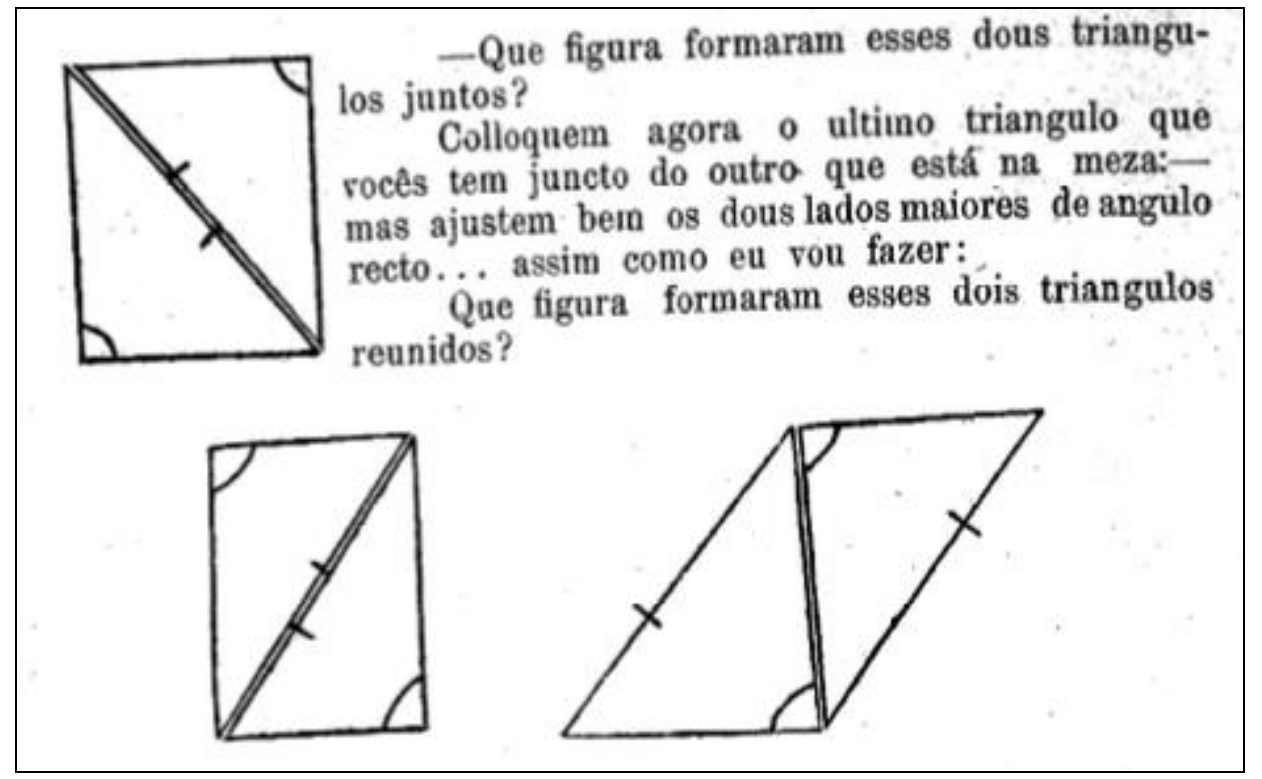

Prestes, 1896, p. 382

De maneira também intuitiva, com cortes e composições de figuras, o autor apresenta a medida da superfície do triângulo como metade da superfície do paralelogramo. Para finalizar o artigo, Gabriel Prestes ressalta que "essas simples indicações bastam para mostrar que de um modo concreto podem ser ensinados os princípios fundamentais da Geometria" (PRESTES, 1896, p. 387) 
Prestes aconselha aos professores, que em suas práticas pedagógicas, eles devam considerar mais as circunstâncias de seus alunos do que os exemplos sugeridos no presente artigo, mas, no entanto, o essencial é manter a ordem do ensino e os meios concretos de demonstrações. Destaca ainda, a dificuldade dos alunos na passagem da noção de altura do retângulo para o caso dos paralelogramos, de modo que o professor possa elucidar.

Pode-se configurar a proposta de Prestes como um estudo de grandezas e medidas abordado em atividades práticas, com a participação efetiva dos alunos de modo a compreender as sistematizações, de uso de material concreto, recortes, figuras, que favoreçam o entendimento da noção de área de uma superfície. De maneira similar, especial atenção é dada para a apresentação de fórmulas, como as de cálculo de áreas de paralelogramos e triângulos, demonstradas intuitivamente.

Certamente, a proposta de Gabriel Prestes teve o intuito de valorizar práticas pedagógicas que envolvem exploração, descoberta, problematizações, manipulações de objetos, a possibilidade do ensino de noções de geometria de maneira intuitiva. Tudo indica que uma proposta como tal, no final do século XIX, tenha se revelado como inovadora, diante de uma pedagogia tradicional, pautada em definições e memorizações.

Entretanto, justamente no momento da publicação de uma proposta inovadora do ensino de geometria, o papel de liderança atribuído a ele sofre transformações, que o levam se distanciar das questões educacionais:

A partir de 1895, mudanças nas orientações políticas, Gabriel não dispõe mais de amplo incentivo e apoio governamental. Em 1898, descontente com a nova regulamentação da instrução pública e as críticas à organização do Curso Normal, Prestes retira-se da direção da escola Normal da Praça, distancia-se do ensino público, mergulhando em uma fama brumosa - as iniciativas de Prestes são confundidas com as de Caetano de Campos (MONARCHA, 1999, p. 215)

\section{À guisa de conclusão}

Tudo indica que a perda de poder político e afastamento de Gabriel Prestes da Educação são fatores que corroboram para que a sua proposta de uma geometria intuitiva não tenha feito escola, haja vista que a taquimetria, ou ainda, o estudo das áreas de superfícies e volumes de sólidos manteve-se durante todo o período nos anos finais do curso primário, $3^{\circ} \mathrm{e}$ $4^{\circ}$ anos escolares, conforme a dissertação de Frizzarini (2014) que analisou os programas de ensino de São Paulo entre 1894 a 1949/50.

No entanto, ideias e propostas pautadas no ensino prático, com a participação dos alunos, uso de recortes, moldes, trabalho com sobreposição e composições de figuras, como o exemplo para o ensino de medida de áreas de superfícies são possibilidades de um ensino intuitivo que circularam em revistas, assim como em manuais, desde o final do século XIX no Brasil. Igualmente relevante é observar que tais propostas são inseridas em um movimento pedagógico mais amplo, de âmbito internacional, como salienta o próprio Gabriel Prestes, que explicita a importância do contato com a obra francesa de Paul Bert. 
Retoma-se aos dias atuais e encontra-se a demanda por práticas efetivas de medições, relatos de dificuldades dos alunos no uso de fórmulas de cálculo de áreas sem compreensão de seu significado. Em que medida, conhecer o passado, tomar contato com experiências e propostas já realizadas, pode trazer contribuição aos professores de hoje? Não se trata de avaliar o passado, de tecer críticas ou lastimar o fato de propostas de caráter intuitivo, com apelo para as atividades práticas não ter sido aceito na cultura escolar da época. Propõe-se pensar e conhecer os saberes matemáticos elementares do passado em seu contexto histórico, em sua articulação com o movimento internacional, sem, contudo, deixar de lado, a característica particular da cultura brasileira, perceber que a institucionalização da expertise participa poderosamente da produção de novos saberes no campo pedagógico, porém seu processo de legitimação, de reconhecimento por seus pares é longo, complexo e conflituoso. Está em jogo a criação e consolidação de um novo campo disciplinar, a história da educação matemática, na qual os saberes ocupam papel central no processo de institucionalização da formação de professores.

Quiçá, no Século XXI, a proposta de um ensino prático para as medidas defendida pelo PNAIC tenha uma trajetória distinta da geometria intuitiva de Gabriel Prestes no final do século XIX.

\section{Referências}

BARBOSA, Rui. Reforma do Ensino Primário e várias Instituições Complementares da Instrução Pública. Obras Completas de Rui Barbosa. Vol. X. 1883, tomo II. Rio de Janeiro: Ministério da Educação e Saúde, 1946.

BASTOS, Maria Helena Camara. Apresentação. FROEBEL, Friederich W. A. A Educação do Homem. Tradução Maria Helena Camara Bastos. Passo Fundo: Universidade de Passo Fundo, 2001.

BASTOS, Maria Helena Camara. Ferdinand Buisson no Brasil - Pistas, vestígios e sinais de suas idéias pedagógicas (1870-1900). História da Educação. ASPHE/FaE/UFPel. Pelotas (8), set., p. 79-109, 2000.

BRASIL. Secretaria de Educação Básica. Diretoria de Apoio à Gestão Educacional. Pacto Nacional pela Alfabetização na Idade Certa: Grandezas e Medidas / Ministério da Educação, Secretaria de Educação Básica, Diretoria de Apoio à Gestão Educacional. Brasília: MEC, SEB, 2014.

CARVALHO, Martha. Maria Chagas de. Modernidade pedagógica e modelos de formação docente. São Paulo em Perspectiva. São Paulo, v. 14, n.1, p. 111-120, 2000.

FRIZZARINI, Claudia Regina Boen. Do ensino intuitivo para a escola ativa: os saberes geométricos nos programas do curso primário paulista. Dissertação (Mestrado em Educação e Saúde) - Universidade Federal de São Paulo, Guarulhos, 2014.

FRIZZARINI, Claudia Regina Boen; LEME DA SILVA, Maria Célia. Saberes geométricos de Calkins e sua apropriação nos programas de ensino dos grupos escolares paulistas. Revista Brasileira de História da Educação. Maringá-PR, v. 16, n. 3 (42), p. 10-35, jul./set., 2016. 
GARNICA, Antonio Vicente Marafioti. Sobre o lugar da História na formação de Professores de Matemática: um ensaio. Revista de investigação e divulgação em Educação Matemática. Juiz de Fora, v.1, n.1, p.27-50, jul. /dez. 2017.

HOFSTETTER, Rita; SCHEUWLY, Bernard; FREYMOND, Mathilde de; BOS, François. Penetrar na verdade da escola para ter elementos concretos de sua avaliação - A irresistível institucionalização do expert em educação (século XIX e XX). In: HOFSTETTER, Rita; VALENTE, Wagner Rodrigues (Org.). Saberes em (trans)formação: tema central da formação de professores. São Paulo: Livraria da Física, p. 55-112, 2017.

MONARCHA, Carlos. Escola Normal da Praça: o lado noturno das luzes. Campinas, SP: Editora da UNICAMP, 1999.

OLIVEIRA, Maria Cristina de Araújo. História da educação matemática como disciplina na formação de professores que ensinam Matemática. Cadernos de História da Educação. v.16, n.3, p.653-665. Set.-dez. 2017. http://dx.doi.org/10.14393/che-v16n3-2017-6

PRESTES, Gabriel. Noções intuitivas de geometria elementar para o terceiro anno de ensino preliminar. A Eschola Publica. São Paulo, SP, ano 1, n.3, p. 251-269, set. 1896. Disponível em: <https://repositorio.ufsc.br/handle/123456789/126751>. Acessado em: 16 de fevereiro de 2017.

PRESTES, Gabriel. Noções Intuitivas de Geometria Elementar. São Paulo: Editor Horacio Belfort Sabino, 1985. Disponível em: <https://repositorio.ufsc.br/xmlui/handle/123456789/ 159285>. Acessado em: 16 de fevereiro de 2017.

SÃO PAULO. Trecho do Decreto n. 248 de 26 de Julho de 1894. Aprovado por Bernardino de Campos e assinado pelo Dr. Cesário Motta Junior. Disponível em: <https://repositorio.ufsc.br/handle/123456789/99544>. Acessado em: 28 de fevereiro de 2017.

SCHUBRING, Gert. A produção internacional em história da educação matemática. Anais do I ENAPHEM. Vitória da Conquista, BA, 2012.

SOUZA, Rosa de Fatima. Alicerces da pátria: História da escola primária no Estado de São Paulo (1890-1976). Campinas, SP: Mercado de Letras, 2009.

TROUVÉ, Alan. La notion de savoirélémentaire à l'école. Paris: L’Harmattan, 2008. 